\title{
Microeconomic Flexibility in India and Pakistan: Employment Adjustment at the Firm Level
}

\section{Theresa Chaudhry*}

\begin{abstract}
In this paper, we look at the pace at which firms adjust their employment levels as a measure of "microeconomic flexibility." Flexibility aids in creative destruction processes, where less efficient establishments recede and dynamic firms can rapidly expand. Following the techniques used by Caballero, Engel, and Micco (2004), we use firm-level data from India and Pakistan to estimate the proportion of the gap closed in a year between desired and actual employment. The results for the proportion of the gap closed for India were 0.46 in 2001 and 0.45 in 2000. For Pakistan, we estimated the proportion of the gap closed as 0.2 in 2001 and 0.53 in 2000. The results for 2001 were much lower than expected land lower than previous estimates for both countries), possibly due to the events of 9/11. Pakistan compared favorably to India in various key sectors, including chemicals, food processing, and garments. Exporters did not seem to have a quicker speed of adjustment.
\end{abstract}

JEL Classification: E2, J2, J6.

Keywords: Costs, efficiency, flexibility, inputs, labor.

\section{Introduction and Literature Review}

There are many ways of looking at allocative efficiency at the microeconomic level, particularly in a static model. However, in this paper, we examine one aspect of dynamic allocative efficiency, referred to as "microeconomic flexibility" by Caballero, Engel, and Micco (2004), henceforth CEM (2004). In order to examine microeconomic flexibility, we are going to look at how quickly firms adjust to economic changes.

In the short run, firms can change output by adjusting variable inputs, most importantly labor. However, due to adjustment costs, firms are not usually able to shift immediately to the new optimal (i.e., profit

* Associate Professor, Department of Economics, Lahore School of Economics, Lahore, Pakistan. 
maximizing) level of labor. In this paper, we look at the speed of adjustment in employment as a measure of microeconomic flexibility.

Flexibility within firms is deemed important, most significantly for economic growth. Flexibility aids in "creative destruction" processes, where less efficient establishments recede and dynamic firms can rapidly expand. An additional benefit is that more flexible economies can quickly take advantage of new opportunities when opening up to trading partners, possibly leading to a first mover advantage. Without flexibility, there is a less efficient allocation of resources, which leads to lower total output. For an example at the industry level, one can see the impact of the lack of flexibility on the part of US automakers in recent years; inflexibility with regard to supply chains and labor contracts compounded the economic difficulties the industry was already facing.

In this paper, we measure economy-level microeconomic flexibility by calculating the speed of adjustment in labor in India and Pakistan. Auxiliary issues that can be addressed include comparing the relative flexibility in India versus Pakistan in key industries, and whether exporters are generally more flexible.

The basis for such research on the microanalysis of employment dynamics was initiated by Caballero and Engel (1993) and extended by Caballero, Engel, and Haltiwanger (CEH) (1997). CEH 1997 used quarterly plant-level data from the US, finding that, from 1972-1980, $90 \%$ of an employment gap (between desired and actual employment levels) was adjusted for in a 1-year period.

Caballero, Cowan, Engel, and Micco (2004), henceforth CCEM (2004), used sector-level data from 1963-2000 and calculated the annual speed of labor force adjustment, controlling for labor regulation. The adjustment coefficient (measured as the percentage of the gap between desired and actual employment closed in 1 year) was calculated for 60 countries, including India and Pakistan, the focus of our paper. They found similar rates for India and Pakistan, with firms on average closing $74.6 \%$ and $77.1 \%$ of the gap between desired and actual employment respectively. Caballero, Engel, and Micco (CEM) 2004 used firm-level data from five Latin American countries to estimate flexibility and the cost (in terms of lost GDP growth) of slow adjustment. Our paper, also utilizing firm-level data, most closely follows the methodology of CEM 2004. 
This methodology is not without its critics. Cooper and Willis (2004a, 2004b) suggest that measurement errors (in computing the gap between desired and actual employment) drive the results of CEH (1997).

\section{Measuring Microeconomic Flexibility: Determination of the Gap ${ }^{1}$}

According to CEM (2004), a firm's output function (1) and demand function (2) can be described (with all variables in log-form) as:

$$
\begin{aligned}
& y=a+\alpha e+\beta b \\
& p=d-(1 / \eta) y
\end{aligned}
$$

Where $y$ =output, $p=$ price, $e=$ employment, $a=$ productivity, $b=$ hours worked, $d=$ demand shock, $\eta=$ price elasticity of demand.

Wages are paid according to the number of hours worked, and given by the following expression:

$$
w=w^{0}+\mu(h-\bar{h})
$$

If adjustment costs are incurred only when changing the number of employees (but not when altering the number of hours worked by the current workforce), then the following expression can be derived, relating the employment gap to the marginal labor productivity gap:

$$
\hat{e}-e=\frac{\varnothing}{1-\alpha \gamma}\left(v-w^{0}\right)
$$

Where $\varphi=\mu /(\mu-\alpha \beta), \gamma=(\eta-1) \eta$, and $v=$ marginal productivity.

From (4), the equation estimated in CEM (2004) is:

$$
\Delta e m p_{i j t}=\alpha+\lambda\left[G a p_{i j t}+\delta_{t}\right]+\varepsilon_{i j t}
$$

Where:

$\Delta e m p_{i j t}$ is the change in employment in firm $i$, sector $j$, at time $t$

$G a p_{i j t}$ represents the difference between actual and optimal employment in firm $i$, sector $j$, at time $t$

\footnotetext{
${ }^{1}$ The following discussion is taken directly from the theoretical model laid out in CEM (2004).
} 
$\lambda$ is the measure of adjustment speed, or microeconomic flexibility, and is measured by the percentage of the gap closed in a year, and

$\varepsilon_{i j t}$ is the error term

$G a p_{i j t}$ is defined as $\frac{\varphi}{1 \alpha \gamma_{j}}\left(v_{i j t}-v_{\cdot j t}-\theta_{i j t}\right)+\Delta e_{i j t}$ where

$\phi=0.4$, as estimated in CCEM (2004) and CEM (2004)

$\alpha \gamma_{j}=$ median share of labor in sector $j$ multiplied by the markup, where the markup set as 0.2 as in CCEM (2004)

The critical component of the gap, the difference between firm-level marginal productivity and the wage (adjusted by a moving average of the firm's marginal productivity relative to other firms in the same sector) is similar to a fixed effect. It is expressed as:

$v_{i j t}-v_{\cdot j t}-\theta_{i j t}$, where

$v_{i j t}$ is the marginal productivity of labor in firm $i$, sector $j$, at time $t$

$v_{\cdot j t}$ is average productivity in sector $j$, at time $t$, as a proxy for the wage, and

$\theta_{i j t}$ is the moving average of relative productivity ${ }^{2}$.

\section{Description of the Data}

The data were taken from the 2002 Enterprise Surveys for India and Pakistan. ${ }^{3}$ Each dataset included 1999-2001 plant-level data on sales, employment, and compensation by sector. After cleaning the data, we had 1,099 observations for India and 783 for Pakistan. The data on India included sufficient observations to study automobile components, chemicals, drugs and pharmaceuticals, electrical white goods, electronics, food processing, garments, leather and leather products, machine tools, metals,

${ }^{2} \theta_{i j t}=0.5\left[\left(v_{i j t-1}-v_{\cdot j t-1}\right)+\left(v_{i j t-2}-v_{\cdot j t-2}\right)\right]$

${ }^{3}$ Source: Enterprise Surveys, The World Bank Group. See www.enterprisesurveys.org. The data for India was taken from the Firm Analysis and Competitiveness Survey of India - 2002, a collaboration of the Confederation of Indian Industry and the World Bank Group. The data for Pakistan was taken from the Investment Climate Survey of Pakistan 2002, a joint undertaking of the Small and Medium Enterprise Development Authority and the World Bank Group. 
and textiles. The sectors covered in the analysis for Pakistan included chemicals, electronics, food processing, garments, information technology (IT), leather and leather products, sports goods, and textiles.

The basic data needed for this type of analysis is quite parsimonious; the only required data (at firm level) are revenues, compensation to labor, and employment. In addition, we have included exporter status and ownermanager dummies (for both countries) and percentage of skilled workers (only available for Pakistan) as additional optional control variables.

Summary statistics can be found in Table-1a (for India) and Table-1b (for Pakistan). In both countries, the majority of firms in all sectors (and the vast majority in many sectors) are managed by firm owners.

There is much greater variation in the percentage of exporters across sectors and between the two countries. In India, the percentage of exporters ranges from a low of $3 \%$ (metals) to a high of $44 \%$ (garments). A significant proportion of exporters can also be found in the pharmaceutical, leather goods, machine tools, and textile sectors.

Among firms in the Pakistan sample, the proportion of exporters ranges from $8 \%$ (chemicals) to $77 \%$ (sports goods). Producers of electronics, garments, IT, and leather goods also have significant proportions of exporters. Surprisingly, in this sample, the proportion of textile exporters is low at $10 \%$.

Comparing the sectors for which there are data for both countries, we can see that the chemical and textile firms surveyed from India are on average larger (in terms of revenues and employees) and more likely to export than firms from the same sector in Pakistan. Electronics and food processing firms are similar in terms of the average number of employees and propensity to export across the two countries. On the other hand, leather and leather goods firms tend to be larger among the Pakistani firms surveyed. 
Table-1a: Summary Statistics - India

\begin{tabular}{lcccccc}
\hline \multicolumn{1}{c}{ Sector } & $\begin{array}{c}\text { Number Exporters } \\
\text { of firms }\end{array}$ & $\begin{array}{c}\text { Owner- } \\
\text { managers } \\
\text { (\%) }\end{array}$ & $\begin{array}{c}\text { Avg. sales } \\
\mathbf{1 9 9 9 - 2 0 0 1} \\
\text { (in } \mathbf{0 0 0} \text { of } \\
\text { PKR) }\end{array}$ & $\begin{array}{c}\text { Avg. \# } \\
\text { employees }\end{array}$ & $\begin{array}{c}\text { Avg. marginal } \\
\text { productivity } \\
\text { (2001) }\end{array}$ \\
(in 000 of PKR)
\end{tabular}

Note: Sales and marginal productivity are in inflation-adjusted PKR for the year 2000. 
Table-1b: Summary Statistics - Pakistan

\begin{tabular}{lcccccc}
\hline \multicolumn{1}{c}{ Sector } & $\begin{array}{c}\text { Number of Exporters } \\
\text { firms }\end{array}$ & $\begin{array}{c}\text { Owner- } \\
\text { (\%) }\end{array}$ & $\begin{array}{c}\text { Avg. sales } \\
\text { managers } \\
\text { (\%) }\end{array}$ & $\begin{array}{c}\text { 1999-2001 } \\
\text { (in } \mathbf{0 0 0} \text { of } \\
\text { PKR) }\end{array}$ & $\begin{array}{c}\text { Avg. \# } \\
\text { employees }\end{array}$ & $\begin{array}{c}\text { Avg. marginal } \\
\text { productivity } \\
\text { (2001) }\end{array}$ \\
(in '000 of PKR)
\end{tabular}

Note: Sales and marginal productivity are in inflation-adjusted PKR for the year 2000 .

\section{Results and Discussion}

CEM (2004) analyzed panel data for five Latin American countries, ranging from 3 to 6 years. Since we only had 3 years of data, we could only run the regression with the correct specification for one year, 2001, because we needed to use two previous years' data (1999-2000) to construct the moving average of the firm's relative productivity. The average productivity for each sector was measured for each country separately.

Since we only estimate the equation for 1 year, we modify the estimated equation (5) for India and Pakistan separately as follows, dropping the time dimension:

$$
\Delta e m p_{i j}=c+\lambda\left[G a p_{i j}\right]+\varepsilon_{i j}
$$


Table-2: Estimates of $\lambda$ (Speed of Adjustment/Flexibility) For All Firms in 2001

\begin{tabular}{lcccc}
\hline & $\begin{array}{c}\text { India } \\
(\mathbf{1})\end{array}$ & $\begin{array}{c}\text { India } \\
(\mathbf{2})\end{array}$ & $\begin{array}{c}\text { Pakistan } \\
\mathbf{( 3 )}\end{array}$ & $\begin{array}{c}\text { Pakistan } \\
\mathbf{( 4 )}\end{array}$ \\
\hline$\lambda$ & 0.45 & 0.42 & 0.2 & 0.2 \\
& $(4.1)$ & $(3.8)$ & $(6.7)$ & $(6.6)$ \\
Exporter dummy & & 0.01 & & 0.001 \\
& & $(0.7)$ & & $(0.1)$ \\
Owner-manager dummy & & -0.01 & & -0.004 \\
& & $(-0.9)$ & & $(-0.5)$ \\
\% Skilled workers & & & & -0.0001 \\
& & & & $(-1.4)$ \\
Adj. R ${ }^{2}$ & 0.34 & 0.33 & 0.16 & 0.16 \\
Observations & 1099 & 1079 & 873 & 872 \\
\hline
\end{tabular}

Note: t-statistics are in parentheses, based on robust standard errors, clustered by sector. The outliers for marginal productivity (top and bottom $0.5 \%$ ) were dropped.

Initially, we ran the regression for only 1 year, i.e., 2001, following the specification of CEM (2004) (see Table-2). However, given the events of 9/11 (with the accompanying economic uncertainty) and the odd results for Pakistan in 2001, we also ran the regressions for the year 2000, using only the 1999 data as a proxy for the firm's relative productivity (Table-3). According to CEM (2004), not properly adjusting for the firm's relative productivity should bias the flexibility coefficient downward.

The results were unchanged when controlling for other potential covariates, including exporters and owner-managed firms. The hypotheses here are that exporters (facing greater competition from foreign rivals) and owner-managers (where there is a closer relationship between pay and performance than hired managers) would have greater incentives to adjust employment to profit-maximizing levels more quickly. These controls were almost universally statistically insignificant, except for the percentage of skilled workers in the Pakistan 2000 regression where there was a small negative effect on employment adjustment (Table-3, Column 4).

Our measurements of 2000 adjustment speeds should be seen as a lower bound of the true adjustment speed. Even so, Pakistan's speed of adjustment in 2000 was calculated as 0.52 . Therefore, we can speculate that the true speed of adjustment (as a measure of flexibility) for both India and Pakistan in a normal year is likely to be in the range 0.5 to 0.6 , meaning 
that more than half the needed labor force adjustment is made in 1 year. $^{4}$ These numbers are somewhat lower than results obtained in CCEM's 2004 analysis, which was sector-1eve1 (not firm-leve1).

Table-3: Estimates of $\lambda$ (Speed of Adjustment/Flexibility) For All Firms in 2000

\begin{tabular}{lcccc}
\hline & $\begin{array}{c}\text { India } \\
(\mathbf{1})\end{array}$ & $\begin{array}{c}\text { India } \\
\mathbf{( 2 )}\end{array}$ & $\begin{array}{c}\text { Pakistan } \\
\mathbf{( 3 )}\end{array}$ & $\begin{array}{c}\text { Pakistan } \\
\mathbf{( 4 )}\end{array}$ \\
\hline$\lambda$ & 0.46 & 0.46 & 0.53 & 0.52 \\
& $(4.6)$ & $(4.7)$ & $(8.8)$ & $(8.8)$ \\
Exporter dummy & & 0.02 & & -0.003 \\
& & $(1.5)$ & & $(-0.2)$ \\
Owner-manager dummy & & -0.002 & & 0.03 \\
& & $(-0.2)$ & & $(1.5)$ \\
\% Skilled workers & & & & -0.0008 \\
Adj. R & & & & $(-3.1)$ \\
Observations & 0.3 & 0.3 & 0.35 & 0.37 \\
\hline
\end{tabular}

Note: $\mathrm{t}$-statistics are in parentheses, based on robust standard errors, clustered by sector. The outliers for marginal productivity (top and bottom $0.5 \%$ ) were dropped.

We also looked at speeds of adjustment in some of the individual sectors for which we were able to compare across the two countries (Table4). From Table-4, one can see that, in textiles, India's firms adjust more quickly, but in chemicals and garments, Pakistan has a micro-flexibility advantage.

${ }^{4}$ However, further analysis with a larger data set would be needed to draw such a conclusion definitively. 
Table-4: Estimates of $\lambda$ (Speed of Adjustment/Flexibility) by Sector

\begin{tabular}{lccc}
\hline & $\begin{array}{c}\text { Pakistan } \\
\mathbf{( 2 0 0 0 )}\end{array}$ & $\begin{array}{c}\text { India } \\
\mathbf{( 2 0 0 0 )}\end{array}$ & $\begin{array}{c}\text { India } \\
\mathbf{( 2 0 0 1 )}\end{array}$ \\
\hline Chemicals & 0.71 & 0.54 & 0.33 \\
& $(2.4)$ & $(3.5)$ & $(2.2)$ \\
Food Processing & 0.37 & 0.38 & 0.28 \\
& $(3.1)$ & $(2.5)$ & $(2.9)$ \\
Garments & 0.75 & 0.49 & 0.43 \\
& $(2.2)$ & $(3.4)$ & $(5.1)$ \\
Textiles & 0.46 & 0.53 & 0.34 \\
& $(2.9)$ & $(3.6)$ & $(2.2)$ \\
\hline
\end{tabular}

Note: t-statistics are in parentheses, based on robust standard errors; Pakistan regressions controlled for percentage of skilled workers, export status and owner-manager dummies. India regressions controlled for export status and owner-manager dummies.

\section{Conclusions}

In this paper, we measured microeconomic flexibility as the proportion of the gap closed in a year between desired and actual employment. The results for the proportion of the gap closed for India were 0.46 in 2001 and 0.45 in 2000. For Pakistan, we estimated the proportion of the gap closed as 0.2 in 2001 and 0.53 in 2000 . The results for the year 2000 were likely biased downward because only 1 year (rather than 2 years) of data was used to construct the average sector productivity. However, the results for 2001 (which used the correct specification) appear to be much lower than expected, possibly impacted by the events of $9 / 11$.

This study has some limitations, notably the limited size of the dataset. The sample is relatively small, and only covers selected industries and regions. In addition, we were only able to run the regression for 1 year with the complete specification, because 2 years of data is used to construct the moving average of marginal productivities. ${ }^{5}$

Given these limitations, we can make some tentative conclusions. Pakistan compares favorably to India in various key sectors, including chemicals, food processing, and garments, based on the limited data that we worked with. Surprisingly, exporters do not seem to have a quicker speed of adjustment.

${ }^{5}$ The World Bank Enterprise Surveys also has a 2005 dataset for India (covering 20022004), which can be used in the future to lengthen the time series for India, as long as there are a sufficient number of firms common across the two datasets. 


\section{References}

Caballero, R., Cowan, K., Enge1, E., and Micco, A. (2004). Effective Labor Regulation and Microeconomic Flexibility. Cowles Foundation Yale University Discussion Paper \#1480.

Caballero, R. and Engel, E. (1993). Microeconomic Adjustment Hazards and Aggregate Dynamics. Quarterly Journal of Economics, 108 (2) : 359-83.

Caballero, R., and Enge1, E. (2004). A Comment on the Economics of Labor Adjustment: Mind the Gap: Reply. American Economic Review, 94 (4) : 1238-1244.

Caballero, R., Enge1, E., and Haltiwanger, J. (1997). Aggregate Employment Dynamics: Building from Microeconomic Evidence. American Economic Review, 87 (1) : 115-137.

Caballero, R., Engel, E., and Micco, A. (2004). Microeconomic Flexibility in Latin America. Department of Economics MIT Working Paper \#04-09.

Cooper, R., and Willis, J. (2004a). A Comment on the Economics of Labor Adjustment: Mind the Gap. American Economic Review, 94 (4) : 1223-1237.

Cooper, R., and Willis, J. (2004b). A Comment on the Economics of Labor Adjustment: Mind the Gap: Rejoinder. American Economic Review, 94 (4) : 1245-1247. 